\title{
FORMAÇÃO DE PROFESSORES E EDUCAÇÃO INTERCULTURAL: Concepções e Práticas de Licenciandos sobre Diversidade Cultural na Educação Básica
}

\author{
Caio Roberto Siqueira Lamego ${ }^{1}$ \\ Maria Cristina Ferreira dos Santos ${ }^{2}$
}

\begin{abstract}
RESUMO
O objetivo deste estudo foi compreender concepções sobre questões culturais e práticas de futuros professores em estágio de docência em uma escola pública estadual no Rio de Janeiro. A pesquisa foi de natureza qualitativa, tendo sido realizadas entrevistas semiestruturadas com cinco estudantes de cursos de Licenciatura de Geografia, Biologia e Matemática. Os depoimentos foram analisados com apoio em autores que tratam de formação e prática docente, articulando-se ao enfrentamento de preconceito e discriminação na abordagem da educação intercultural. A análise dos relatos indicou obstáculos que dificultavam as práticas pedagógicas. Mesmo com o desenvolvimento de projetos e debates que buscavam enfrentar o preconceito e a discriminação na escola, nos depoimentos evidenciaram-se os preconceitos raciais e de gênero, sendo naturalizados pelo daltonismo cultural dos sujeitos na forma de "brincadeiras". Práticas dialógicas foram apontadas como estratégias norteadoras das discussões sobre abordagens culturais. Ressalta-se a importância de uma formação pedagógica para a atuação docente capaz de desnaturalizar o preconceito e a discriminação na escola.
\end{abstract}

Palavras-chave: Formação docente. Educação básica. Diversidade. Diferença.

TEACHER TRAINING AND INTERCULTURAL EDUCATION:

Undergraduate Students' Conceptions and Pratices on Cultural Diversity in Elementary Education

\begin{abstract}
The objective of this study was to understand undergraduate students' conceptions about cultural issues and practices in teaching at a state public school in Rio de Janeiro. The research was qualitative and semi-structured interviews were carried out with five undergraduate students in Geography, Biology and Mathematics. The interviews were analyzed with emphasis on authors who deal with training and teaching practice, as well as confronting prejudice and discrimination, based on the intercultural education approach. The reports'analysis indicated obstacles that hampered pedagogical practices. Even with the development of projects and debates that sought to face prejudice and discrimination in school, the analysis indicated racial and gender prejudices, being naturalized by cultural daltonism of the subjects in the form of "jokes". Dialogical practices were pointed as guiding strategies of the discussions about cultural approaches. It is important to emphasize a pedagogical formation for the teaching activity capable of denaturalizing prejudice and discrimination in the school.
\end{abstract}

Keywords: Teacher training. Elementary education. Diversity. Diference.

RECEBIDO EM: 15/2/2019

ACEITO EM: 2/4/2019

\footnotetext{
${ }^{1}$ Doutorando em Ensino em Biociências e Saúde pelo Instituto Oswaldo Cruz (Fiocruz). Mestre em Ensino de Ciências, Ambiente e Sociedade e graduado em Ciências Biológicas pela Universidade do Estado do Rio de Janeiro. Docente da Secretaria de Estado de Educação e da Secretaria Municipal de Educação e Cultura de Itaboraí, RJ, Brasil. Integrante do Grupo de Pesquisa: Ensino, Formação, Currículos e Culturas. http://lattes.cnpq.br/2690387015168569. Orcid: https://orcid.org/0000-0002-5184-1518. caiolamego@gmail.com

2 Doutora em Educação pela Universidade Federal Fluminense. Mestre e graduada em Ciências Biológicas pela Universidade Federal do Rio de Janeiro. Professora da Universidade do Estado do Rio de Janeiro. Docente dos Programas de Pós-Graduação em Ensino de Ciências, Ambiente e Sociedade e de Ensino em Educação Básica na Uerj, RJ, Brasil. Líder do Grupo de Pesquisa: Ensino, Formação, Currículos e Culturas. http://lattes.cnpq.br/2005558866313073. Orcid: https://orcid.org/0000-0003-4522-1109. Researcher ID: http://www.researcherid.com/ rid/O-3378-2015. mariacristinauerj@gmail.com
} 
O estudo com foco na cultura é relevante para se entender as dinâmicas dos sujeitos socioculturais. $\mathrm{O}$ olhar atento para noções importantes da educação intercultural - identidade, diferença e tolerância - é possível quando há comprometimento de uma prática pedagógica que preze pelo diálogo entre as perspectivas culturais dos diferentes sujeitos envolvidos no processo educativo. Fleuri (2001, p. 48) afirma que "[...] a complexidade das relações sociais e interculturais no mundo contemporâneo requer novas formas de se elaborar o conhecimento no campo da pesquisa em educação". Para Lamego e Santos (2018, p. 112), colocando a diversidade cultural no centro de debates é possível tecer "[...] reflexões sobre sociedade e educação, representando desafios e conquistas no atual cenário educacional".

A escola é um ambiente que muitas vezes busca homogeneizar e padronizar os indivíduos, justificando, assim, a igualdade entre os sujeitos envolvidos no processo educativo. Ações assimilacionistas na escola não valorizam vozes subalternizadas e têm negado a diversidade cultural neste espaço, tendendo a silenciar ou neutralizar as diferenças pela dificuldade de lidar com a diversidade ali existente (MOREIRA; CANDAU, 2003). Segundo Ferreiro (1994), as ações promovidas pela escola ainda refletem aquelas adotadas no século 19, em que a instituição escolar buscava promover uma política de igualdade sem considerar as diferenças individuais dos sujeitos que conviviam em seu espaço, ou seja, equiparando igualdade com homogeneidade. Para essa autora, o papel da escola, herdado daquela época, se encarrega de "[...] homogeneizar, igualar, sem poder apreciar as diferenças" existentes entre os sujeitos socioculturais que ali convivem. Martinazzo, Schmidt e Burg (2014, p. 7) propõem que a escola deve exercer o papel de ambiente democrático onde há reconhecimento e valorização das diferenças, contribuindo na "[...] formação de cidadãos conscientes dessa realidade e que se compreendam em sua identidade", sem que estes sujeitos sejam inferiorizados pelas suas diferentes identidades culturais.

A abordagem de temas que permeiam questões étnico-raciais, questões religiosas, de gênero e sexualidade, educação de povos tradicionais, entre outros, suscita novos debates e reflexões a fim de tencionar o papel homogeneizador da escola na sociedade atual. Moreira e Candau (2003) afirmam que a relação existente entre escola e cultura está presente em todo o processo educativo e ressaltam a importância da construção de um currículo dotado de novas posturas, saberes, objetivos, conteúdos, estratégias e formas de avaliação, colocando a cultura como o cerne do processo de ensino e aprendizagem. Quando se reconhece essa relação e há o reconhecimento das diferenças entre os sujeitos, torna-se fecunda a construção de novas posturas e a valorização do debate sobre igualdade na diferença. Para Andrade (2012, p. 3), "[...] afirmar a igualdade não pode significar, em hipótese nenhuma, negar a diferença que nos caracteriza", pois "[...] o discurso sobre a igualdade nem sempre expressa plenamente a nossa condição humana, que é marcada fundamentalmente pela diversidade". O intercâmbio dialético impulsiona a reflexão sobre a diferença que nos caracteriza e a igualdade dentro de uma perspectiva da diversidade de culturas a partir do ponto de vista do multiculturalismo existente na sociedade contemporânea. 
O multiculturalismo vem adquirindo "[...] maior abrangência, visibilidade e conflitividade" (CANDAU, 2002, p. 126) no âmbito das diferenças culturais que são componentes fundamentais das relações sociais cotidianas no que se refere "[...] às relações interpessoais quanto entre diversos grupos e movimentos presentes na sociedade" (CANDAU, 2014a, p. 23). O multiculturalismo incluiu-se no debate relacionado aos aspectos da diversidade "cultural/linguística/identitária" e também em resposta "[...] aos diferentes movimentos sociais que representam vozes em busca de direitos e legitimidade" (CANEN; ARBACHE; FRANCO, 2001, p. 164). Canen e Oliveira (2002, p. 61) afirmam que "[...] o projeto multicultural insere-se em uma visão pós-moderna de sociedade, em que a diversidade, a descontinuidade e a diferença são percebidas como categorias centrais". Para as autoras, o multiculturalismo se contrapõe à visão moderna e iluminista de identidade, "[...] como uma essência, estável e fixa", pois reconhece o processo identitário como algo "[...] descentrado, múltiplo e em processo permanente de construção e reconstrução". Fleuri (2001, p. 52) situa a perspectiva multicultural como reconhecimento de "[...] diferenças étnicas, culturais e religiosas entre grupos que coabitam no mesmo contexto [...] entendendo as culturas diferentes como objeto de estudo, como matéria a ser aprendida".

O multiculturalismo tem sua gênese a partir de lutas de grupos sociais subalternizados e marginalizados pela elite hegemônica, buscando reconhecimento e valorização dos sujeitos socioculturais que compõem grupos minoritários. A significância dessas lutas, antes restritas a grupos sociais minoritários, adentra o ambiente escolar objetivando romper com o daltonismo cultural que se caracteriza pelo não reconhecimento da diversidade cultural existente entre os diversos grupos sociais em múltiplas situações. Segundo Candau (2014b, p. 39), o daltonismo cultural “[...] favorece o caráter monocultural da cultura escolar e da cultura da escola, e que tem implicações muito negativas para a prática educativa", sendo uma das mais perversas implicações para os alunos "[...] a excessiva distância entre suas experiências socioculturais e a escola, o que se traduz em elevados índices de fracasso escolar".

Candau (2014a, 2014b) apresenta três concepções de multiculturalismo: a) multiculturalismo assimilacionista, que visa a integrar os diferentes sujeitos à cultura dominante com um discurso de igualdade, mas que favorece o caráter monocultural e homogeneizador; b) multiculturalismo diferencialista ou monoculturalismo plural, que denuncia o processo assimilacionista por entender que este silencia a diferença entre os sujeitos, porém preserva características próprias de uma dada cultura isolando-a das demais; e, c) o multiculturalismo interativo ou interculturalidade, que tem por propósito confrontar aspectos da visão assimilacionista e diferencialista por meio da interação sociocultural de diferentes grupos sociais, pois entende que o diálogo e a reflexão são mecanismos que põem em cena o debate sobre igualdade e diferença sem reduzi-los a polos distintos. Para Santiago, Akkari e Marques (2013, p. 24), a adoção da educação intercultural pode repercutir positivamente no ambiente escolar, "[...] favorecendo o diálogo entre as diferenças e problematizando discursos que essencializam as identidades".

Com relação à educação intercultural, Walsh (2009) propõe a diferenciação em três concepções: a) interculturalidade relacional, que se caracteriza por um contato superficial entre as diferentes culturas; b) interculturalidade funcional, em que há o reco- 
nhecimento da diversidade e diferença, contudo procura inclui-las em uma estrutura organizacional já estabelecida, sem questionamento; e, c) interculturalidade crítica, que busca mudanças nas relações sociais estabelecidas por diferentes sujeitos, de modo a repensar a construção histórico-social de preconceitos e discriminações vindos da formação de uma sociedade pautada na tríade estrutural-colonial-racial e possibilitar o diálogo crítico-reflexivo na diversidade cultural. Entendendo que a interculturalidade crítica favorece a construção de identidades dinâmicas, Sacavino (2012, p. 2) destaca que, atualmente, o principal foco é "[...] a construção de uma perspectiva intercultural capaz de mobilizar práticas educativas que visem uma educação crítica tendo como horizonte a reinvenção da escola".

\section{A FORMAÇÃO INICIAL DE LICENCIANDOS E SUA CONTRIBUIÇÃO PARA UMA EDUCAÇÃO INTERCULTURAL}

A formação de professores e a produção de saberes próprios da profissão docente tem se configurado em objeto de estudo e interesse a partir da segunda metade do século 20, pois "[...] buscava-se atender as demandas do campo educacional para encontrar alternativas que pudessem contribuir para melhorar o desempenho de professores e escolas, na educação das novas gerações, de forma a viabilizar avanços e usufruir as benesses do desenvolvimento científico" (MONTEIRO, 2003, p. 1). A formação docente tem sido investigada sobre múltiplos aspectos, entre eles aqueles que buscam "[...] reconhecer a existência de saberes e fazeres pertinentes ao ato de ensinar, e a compreensão de que eles podem ser objeto de ensino/aprendizagem pelos docentes" (MONTEIRO, 2005, p. 153).

Nóvoa (2001) afirma que a fabricação identitária do professor produz-se em um jogo de poderes e de contrapoderes entre imagens que são portadoras de visões distintas da profissão; ela articula dimensões individuais, que pertencem à própria pessoa do professor, com dimensões coletivas que estão inscritas na história e nos projetos do "corpo docente". Entre as várias situações vivenciadas no cotidiano da escola, torna-se importante refletir sobre o processo de formação dos estudantes, sendo cada vez mais exigida uma prática pedagógica reflexiva acerca do contexto onde o aluno está inserido. A vivência no ambiente escolar tem importância na construção da identidade profissional do docente, contribuindo no seu processo de formação. Marandino, Selles e Ferreira (2009) afirmam que a formação de professores é um processo contínuo que não se define no momento em que o professor recém-licenciado inicia as suas atividades na escola, pois ao longo da trajetória docente vão se construindo novas formas e processos de ensinar. Na formação profissional docente, conhecimentos e atitudes são repensados de modo a dar espaço para a reelaboração de metodologias que atendam às necessidades do processo de ensino e aprendizagem no âmbito escolar, caracterizando os saberes experienciais que, segundo Tardif (2014), são aqueles oriundos do exercício da atividade profissional, pelas vivências na escola e relações com alunos e outros professores, incorporando-se à experiência individual e coletiva. Dessa forma, não cabe associar a formação ao progresso e/ou desenvolvimento, mas, sim, à capacidade de perceber neste processo possíveis retrospectivas, construindo a própria formação a partir das 
experiências vividas (RECH; BREZOLIN; OLIVEIRA, 2012). Uma forma de contribuir para a melhoria da formação docente inicial e continuada é estreitar os laços entre a universidade e a escola.

$\mathrm{Na}$ formação inicial de professores existe distanciamento entre teoria e prática; na Graduação, muitos estudantes cumprem uma rígida grade curricular específica do curso de Licenciatura sem articular os conhecimentos ao cotidiano da escola. Muitos licenciandos vivenciam de forma superficial a realidade escolar, sendo este contato limitado às disciplinas de estágio supervisionado, previstas como requisito básico para o cumprimento da carga horária necessária para a conclusão do curso. O modelo de formação docente ainda se configura pelo distanciamento entre as instituições formadoras e a educação básica, quando há predominância de estudos teóricos sem articulação com a prática docente. Ambrosetti et al. (2013, p. 154) asseveram que "[...] os avanços sobre os saberes envolvidos no trabalho docente vêm levando ao questionamento dos atuais modelos de formação e à busca de alternativas que contemplem uma formação inicial mais articulada aos espaços de exercício profissional".

Para Melo e França-Carvalho (2017, p. 466), “[...] a formação inicial caracteriza-se como um espaço acadêmico no qual o licenciando constrói a sua identidade profissional e adquire saberes da docência", sendo esses saberes fundamentais para uma prática pedagógica que articule os conhecimentos específicos das disciplinas acadêmicas aos saberes escolares, corroborando na construção da cultura escolar. O distanciamento entre universidade e escola na formação inicial de professores diminui as possibilidades de licenciandos compreenderem "[...] as relações humanas que se constroem na dinâmica interativa e peculiar da cada escola" (RAUSCH; FRANTZ, 2013, p. 621).

$\mathrm{Na}$ tentativa de instituir políticas de valorização docente e minimizar o distanciamento existente entre os cursos de Licenciaturas e a educação básica, o Ministério de Educação criou programas que "[...] contribuem com a qualificação inicial de professores" (RAUSCH; FRANTZ, 2013, p. 622). Instituído pela Portaria Normativa no 38, de dezembro de 2007, o Programa Institucional de Bolsas de Iniciação à Docência (Pibid) estabeleceu estratégias que visavam a estimular a integração entre o Ensino Superior e a educação básica por meio de projetos colaborativos, tendo como objetivo a melhoria da qualidade da escola pública (BRASIL, 2007). O Pibid passou a contribuir também para o processo formativo de licenciandos e de docentes na educação básica, pois, segundo Rausch e Frantz (2013, p. 623), com esse projeto "[...] existe a possibilidade de trocas e melhorias nos processos de ensinar e de aprender tanto na educação básica, quanto na universidade". Segundo Barreto (2015, p. 688), os projetos desenvolvidos por este programa de valorização docente visam a "[...] promover a inserção dos estudantes no contexto das escolas desde o início de sua formação em nível superior, com o fito de que eles desenvolvam atividades didático-pedagógicas sob a orientação de um docente da licenciatura e um professor da educação básica". A concessão de bolsas a professores das escolas públicas é um elemento diferencial do Pibid, uma vez que eles "[...] acompanham as atividades dos bolsistas no espaço escolar, atuando como coformadores no processo de iniciação à docência" (AMBROSETTI et al., 2013, p. 159). A concessão de bolsas para o docente traz como benefício a possibilidade de este sujeito obter recursos que podem 
ser utilizados na formação continuada, posto que auxilia o mesmo na aquisição de materiais para leitura e também para o custeio de sua participação em eventos acadêmicos que contribuem para o seu processo formativo.

No Pibid os projetos pedagógicos a serem desenvolvidos nas escolas parceiras necessitam atender a alguns objetivos e metas, visando à inserção dos licenciandos no ambiente escolar e o acompanhamento e avaliação de atividades na escola. O Decreto no 7.219 de 24 de junho de 2010 estabeleceu alguns objetivos a serem alcançados pelos bolsistas e supervisores nas escolas públicas (BRASIL, 2010). Os objetivos são estabelecidos no Artigo 3ㅇ do decreto supracitado:

I - incentivar a formação de docentes em nível superior para a educação básica; II - contribuir para a valorização do magistério; III - elevar a qualidade da formação inicial de professores nos cursos de licenciatura, promovendo a integração entre educação superior e educação básica; IV - inserir os licenciandos no cotidiano de escolas da rede pública de educação, proporcionando-lhes oportunidades de criação e participação em experiências metodológicas, tecnológicas e práticas docentes de caráter inovador e interdisciplinar que busquem a superação de problemas identificados no processo de ensino-aprendizagem; $V$ - incentivar escolas públicas de educação básica, mobilizando seus professores como coformadores dos futuros docentes e tornando-as protagonistas nos processos de formação inicial para o magistério; e VI - contribuir para a articulação entre teoria e prática necessárias à formação dos docentes, elevando a qualidade das ações acadêmicas nos cursos de licenciatura (BRASIL, 2010, p. 4).

A inserção do bolsista na escola está atrelada à sua imersão em um ambiente de diversidade cultural, onde diferentes sujeitos socioculturais convivem e tensionam suas diferentes identidades. Na formação inicial os licenciandos desenvolvem vivências e práticas em espaços sociais em que circulam diferentes sujeitos socioculturais, com suas histórias, culturas e identidades. Experienciar esse espaço com diversidade ainda na formação inicial pode ser um momento fecundo para a promoção da educação intercultural, quando há comprometimento com o diálogo crítico-reflexivo para pensar a escola a partir da sua diversidade. Pesquisas mostram que o desenvolvimento de práticas pedagógicas voltadas para abordagens culturais por subprojetos do Pibid, com vistas ao debate sobre a valorização das diferenças, têm sido importantes para a compreensão de "[...] novas relações entre sujeitos e entre grupos diferentes, empoderando identidades sociais e diferentes grupos socais através de relações críticas e solidárias" (POMMER; SANOS; SOARES, 2016, p. 62), favorecendo a "[...] construção de um projeto comum, pelo qual as diferenças são dialeticamente incluídas" (RIOS; NUÑEZ; FERNANDEZ, 2016, p. 106). Nesse sentido, entende-se que o Pibid pode trazer contribuições para o desenvolvimento de abordagens culturais no ambiente escolar, valorizando a diversidade cultural no encontro entre universidade e escola.

O objetivo deste estudo foi compreender concepções e práticas sobre questões culturais de futuros professores, participantes do Programa Institucional de Bolsas de Iniciação à Docência (Pibid), que realizavam estágio em uma escola estadual no Rio de Janeiro. As inquietações na busca de um olhar intercultural para/na escola estão inseridas nos seguintes eixos norteadores: formação e prática docente, metodologias de ensino, e enfrentamento da discriminação e do preconceito. 


\section{METODOLOGIA}

A pesquisa foi realizada com base na abordagem qualitativa, buscando entender significados, vivências, crenças, valores e atitudes (MINAYO, 2009) de sujeitos sobre abordagens culturais no ambiente escolar. Os dados construídos em uma pesquisa caracterizada como qualitativa referem-se a textos e narrativas oferecidos pelos participantes (BOGDAN; BIKLEN, 1994). Optar por uma análise qualitativa dos dados não exclui a possibilidade de haver apoio quantitativo; Trivinõs (1987) afirma, contudo, que geralmente há omissão das análises estatísticas ou o seu emprego não é refinado. Segundo esse autor, as contribuições da pesquisa qualitativa estão ancoradas na ideia de possibilitar "[...] descobrir as características culturais que envolvem a existência das pessoas que participam da pesquisa" (TRIVIÑOS, 1987, p. 122), potencializando uma análise dos dados não a partir de fatos isolados, mas levando em consideração a objetividade do contexto social em que a pesquisa está sendo desenvolvida.

$O$ instrumento de construção de dados foi a entrevista semiestruturada. O uso de entrevista se justificou por ser um instrumento que permite a captação imediata dos dados, além de permitir aprofundar questões que contribuam para a compreensão das informações disponibilizadas pelo entrevistado (MINAYO, 2013; GIL, 2012). Gil (2012, p. 119) sinaliza que, com o uso desse instrumento, o "[...] entrevistador é capaz de registrar as reações do entrevistado às perguntas que são feitas", sendo "[...] de grande utilidade na análise da qualidade das respostas". Para Duarte (2004), o uso de entrevista em um trabalho científico justifica-se por ser um instrumento fundamental,

[...] quando se precisa/deseja mapear práticas, crenças, valores e sistemas classificatórios de universos sociais específicos, mais ou menos bem delimitados, em que os conflitos e contradições não estejam claramente explicitados (...) permitindo ao pesquisador fazer uma espécie de mergulho em profundidade, coletando indícios dos modos como cada um daqueles sujeitos percebe e significa sua realidade e levantando informações consistentes que lhe permitam descrever e compreender a lógica que preside as relações que se estabelecem no interior daquele grupo [...] (p. 215).

Partindo desse pressuposto, buscou-se compreender concepções e práticas envolvendo abordagens culturais na educação básica, desenvolvidas por estudantes em formação inicial no estágio de iniciação à docência na escola.

O critério de seleção dos participantes foi ser licenciando e participante do Pibid na escola em que o estudo foi realizado. No período de desenvolvimento deste estudo - 2016 a 2018 - três subprojetos do Pibid foram aplicados na escola. No total foram selecionados cinco licenciandos dos três subprojetos e a eles apresentados os objetivos da pesquisa. Após a concordância em participar da investigação, eles assinaram o Termo de Consentimento Livre e Esclarecido (TCLE), atendendo às normas éticas de pesquisa e garantindo o sigilo de sua identidade. Optou-se por diferenciar as suas respostas por meio de um sistema alfanumérico, onde cada participante recebeu para identificação a letra "L", seguida de um número e do código correspondente ao curso de Graduação. Foram entrevistados dois licenciandos do curso de Ciências Biológicas: L1-CB e L2-CB, dois do curso de Geografia: L3-G e L4-G e um do curso de Matemática: L5-M. Cabe ressaltar que a numeração dada às respostas não as hierarquizam no universo da pesquisa. 
As transcrições das narrativas dos licenciandos foram realizadas buscando-se fidelidade aos relatos de cada entrevistado. Após leituras sucessivas das transcrições das entrevistas, as respostas dos licenciandos foram agrupadas em unidades temáticas, de forma que fosse possível categorizá-las a partir de contextos similares (JACOB, 2004; MORAES, 1999). Os dados foram analisados a partir do diálogo com autores que tratam de formação e prática docente, além do enfrentamento de preconceito e discriminação a partir da abordagem da educação intercultural. Para a análise dos dados foi utilizado o método da análise de conteúdo. A classificação foi realizada por critérios que surgiram durante o processo de análise das entrevistas concedidas pelos licenciandos a partir da unitarização da mensagem em suas narrativas (BARDIN, 2016; MORAES, 1999). Por ser uma pesquisa de cunho qualitativo e tendo a entrevista como instrumento de construção de dados, optou-se por proceder ao diagnóstico por meio da análise temática que tem como perspectiva descobrir "[...] 'núcleos de sentidos' que compõem a comunicação e cuja presença ou frequência de aparição pode significar alguma coisa para o objetivo analítico escolhido" (BARDIN, 2016, p. 135). Neste sentido, os temas analisados foram: formação e prática docente, metodologias de ensino, motivações para abordar cultura no espaço escolar, obstáculos encontrados para trabalhar com a abordagem cultural e enfrentamento de discriminação e preconceito.

\section{ANÁLISE DAS NARRATIVAS DOS LICENCIANDOS SOBRE PRECONCEITO, DISCRIMINAÇÃO E DIVERSIDADE CULTURAL NA ESCOLA}

Buscou-se investigar se os licenciandos participantes deste estudo haviam desenvolvido atividades na escola relacionadas a questões culturais e quais as temáticas trabalhadas. Os licenciandos L1-CB, L3-G e L4-G responderam positivamente, contudo L1-CB sinalizou que a atividade realizada ocorreu como parte da avaliação da disciplina Estágio Supervisionado e não no projeto Pibid.

Não foi uma atividade desenvolvida propriamente no Pibid, mas já tive a oportunidade de desenvolver uma oficina sobre questões étnico-raciais, que no momento não me recordo o nome da atividade. Essa oficina foi realizada como uma das atividades propostas em uma disciplina do curso de Licenciatura, que era o Estágio Supervisionado. Foi um momento muito enriquecedor para refletir sobre a pluralidade cultural, pois busquei entender a visão dos alunos sobre este tema. Pensando em cultura, creio que essa atividade contribuiu para os alunos entenderem um pouco mais sobre sua identidade e permitir um diálogo sobre esse tema tão importante que deve ser desenvolvido na escola (L1-CB).

$\mathrm{Na}$ escola eu tive a oportunidade de participar de um evento chamado "Feira das Regiões", que tratou da pluralidade cultural presente no Brasil. Mesmo o Brasil sendo um território, existe nele uma variedade de povos e costumes. Por exemplo, o índio da Região Norte é diferente dos índios da Região Sul e do Nordeste. Podemos perceber também a comunidade quilombola com seus diferentes costumes e que terão influência da localidade onde estão inseridas. Dentro da própria escola conseguimos perceber as diferenças existentes (...) É com o reconhecimento dessa diferença que a escola tem que parar e pensar um projeto pedagógico que consiga dar conta dessa totalidade (L3-G). 
A minha principal experiência foi a "Feira das Regiões", que teve por objetivo discutir sobre as diferentes culturas presentes no Brasil, mas gostaria de desenvolver alguma atividade que pudesse abordar a religião, principalmente por entender que ela tem uma história cultural envolvida e por permitir trabalhar diferentes aspectos, principalmente com os alunos que temos, pois eles vêm de diferentes comunidades (L4-G).

Os licenciandos L2-CB e L5-M relataram nunca ter desenvolvido atividades que envolvessem diferenças culturais na escola, porém o primeiro reconheceu a relevância de se discutir temas que são "[...] abandonados no currículo, como a questão de gênero e as diferentes formas de preconceitos que acontecem na escola, e que não se é falado, sendo importante para que muitas crianças não vivenciassem o racismo e a homofobia, porque esses temas ainda hoje não são discutidos na escola" (L2-CB).

A escola é marcada pela diversidade cultural, onde diferentes sujeitos expressam sua cultura e identidade, sendo por isso fundamental pensá-la como local que promova a "[...] ruptura com modelos únicos e homogêneos", buscando viver "[...] a complexidade do/no cotidiano em sua diversidade e riqueza" (SANTIAGO; AKKARI, MARQUES, 2013, p. 178). Ressalta-se a importância de uma formação pedagógica que se preocupe em formar sujeitos capazes de abordar tais questões na escola, a fim de promover diálogos que incluam a diversidade como tema central para as reflexões e ressignificações das práticas pedagógicas, de modo a contribuir para uma escola menos excludente (MATOS; PERMISÁN, 2016), que reconheça e valorize as diferenças culturais, mas que não as reduza, e sim promova práticas que trabalhem a igualdade na diferença (SACAVINO, 2012). A possibilidade de envolver os licenciandos na escola contribui para que esses sujeitos vivenciem a diversidade presente neste ambiente e busquem desenvolver atividades comprometidas com questões culturais contemporâneas.

Quando se perguntou sobre os saberes mobilizados pelos licenciandos para o desenvolvimento dessas atividades, a análise indicou que eles são resultado de diferentes saberes adquiridos ao longo da vida pessoal e da formação profissional, o que os tornam uma amálgama para fomentar práticas pedagógicas comprometidas com a diversidade cultural existente na escola.

O que me mobiliza é ver que determinadas "brincadeiras" fogem ao limite do respeito. Eu volto e vejo o quanto sofri com essas "brincadeiras" quando era aluna, porém, hoje, como professora, é fundamental tomar uma atitude diante dessas situações que alguns professores ignoravam ou ainda ignoram. Então, entendo que a motivação parte muito dos saberes pessoais e das minhas vivências (L1-CB).

O saber que a pessoa traz na sua estrada de vida seria muito importante, mas respeitando também o saber do aluno. Essa troca entre saberes se torna interessante para trabalhar diferentes questões relacionadas com a diversidade cultural em sala de aula (L2-CB).

Muito está relacionado com os saberes que trazemos de nossas vidas e que se complementam com os saberes acadêmicos. Com esses dois saberes eu fui para a escola e lá acabei aprendendo outros. Eu não posso selecionar apenas um saber por que todos eles são importantes para a nossa formação (L3-G). 
Analisando os depoimentos dos licenciandos, o seu posicionamento, enquanto sujeitos que buscam discutir a diversidade cultural em sala de aula, está relacionado aos saberes pessoais. Segundo Tardif (2014, p. 63), esses saberes se caracterizam "[...] pela história de vida e pela socialização primária" dos sujeitos. A história de vida pode influenciar o tipo de abordagem cultural durante a vida profissional desses futuros professores. Além dos saberes pessoais, os licenciandos evidenciaram a experiência como um importante saber adquirido para lidar com a diversidade presente na escola. Para Campos e Diniz (2001, p. 82), o saber da experiência "[...] é um saber oriundo da prática e sobre a prática" que irá diferir do conhecimento prático, pois este último "[...] envolve um conjunto complexo de conhecimentos orientados para a prática que existe, quer no nível dos argumentos práticos, quer no nível da reflexão na ação". É na socialização com os pares que o professor em formação vivenciará experiências que contribuem para a reflexão sobre a sua atuação e para a construção de sua identidade profissional, com a construção de saberes experienciais ou práticos: "[...] no exercício de suas funções e na prática de sua profissão, desenvolvem saberes específicos, baseados em seu trabalho cotidiano e no conhecimento de seu meio" (TARDIF, 2014, p. 101).

A terceira pergunta buscou compreender quais metodologias de ensino os licenciandos utilizavam ou utilizariam em suas aulas para abordar questões culturais. A análise das respostas aponta o diálogo como uma estratégia pedagógica interessante para abordar diversos temas relacionados à cultura, possibilitando valorizar diferentes sujeitos na construção coletiva de um pensamento crítico-reflexivo sobre distintas temáticas.

Creio que para trabalhar esses temas os debates sejam os melhores, porque eles movimentam o diálogo entre os alunos e aquele que está conduzindo a atividade [...]. Em uma roda onde todos podem falar, as coisas acabam fluindo naturalmente (L1-CB).

A melhor forma de promover um debate sobre temas relacionados à pluralidade cultural é permitir que haja nas escolas rodas de conversa. Por exemplo, não dá para eu falar sobre favela para meu aluno negro e morador de comunidades sendo branco e morando em um bom bairro, mas, quando eu utilizo a roda de conversa para lançar um tema, estou permitindo que haja uma reflexão coletiva sobre o assunto e fazendo com que meu aluno tenha voz naquele momento de diálogo. Aí sim eu estou sendo plural porque na roda cada um vai falar o que quer sobre o assunto que estamos tratando, ou seja, não estou me apresentando como uma figura que está ali em um tablado para dar a minha opinião apenas (L3-G).

As narrativas dos licenciandos que têm como proposta atividades dialógicas para tratar de diferentes temáticas culturais, se aproximam da proposta de educação intercultural, pois se baseiam no diálogo e reflexão coletiva, promovendo respeito e valorizando as diferenças existentes entre os sujeitos socioculturais e rompendo com o discurso de igualdade assimilacionista (CANDAU, 2014a, CANDAU, 2014b; WALSH, 2009). Segundo Andrade (2014, p. 344), é o "[...] diálogo que favorece o conhecimento do outro e de si próprio", de modo a "[...] fortalecer o valor do 'outro significativo' entre todas as culturas, a fim de propiciar o reconhecimento das diferenças como riquezas a serem respeitadas". O diálogo como estratégia pedagógica possibilita "[...] reconhecer que o direito à educação se traduz na participação e na aprendizagem de todos, em todos 
os níveis da educação" (SANTIAGO; AKKARI; MARQUES, 2013, p. 29), contribuindo, de forma significativa, para o desenvolvimento de uma educação intercultural na educação básica.

Em relação aos obstáculos para o desenvolvimento de uma educação intercultural na escola, nas narrativas dos licenciandos notam-se dificuldades para abordar a diversidade cultural, destacando-se as questões religiosas, como explicitado em: "[...] nos debates sobre gênero e etnias; este último por esbarrar na matriz africana" (L3-G), "[...] dialogar sobre religiões de matriz africana é um problema, mesmo existindo uma lei que prevê o ensino de História da África nas escolas ainda existe racismo e preconceito sobre essa cultura" (L4-G). Há visões conflitantes entre as religiões, de modo que o fundamentalismo cristão se mostra proselitista em detrimento de outras formas de manifestação religiosa, sendo as religiões cristãs a expressão religiosa hegemônica na escola (BARCELLOS; ANDRADE, 2014, p. 6). Candau (2011) afirma a necessidade de trazer para a escola um debate sólido sobre as questões sociais, a fim de contribuir para minimizar preconceitos.

Em relação à observação de situações de preconceito e discriminação na escola, nas falas dos licenciandos verifica-se que o preconceito está principalmente relacionado às relações étnico-raciais e à sexualidade dos estudantes. As pesquisas de Saavedra et al. (2003) também sinalizam que esses tipos de discriminação são os prevalentes no ambiente escolar.

Houve uma situação de preconceito racial e, enquanto Pibid, nos posicionamos e procuramos a turma para conversar sobre o ocorrido. O professor supervisor nos apoiou neste momento. Percebi também que os apelidos se "naturalizaram" entre os alunos. $\mathrm{O}$ que mobiliza é exatamente o preconceito que existe dentro do ambiente escolar e que você, enquanto professor, busca dialogar sobre vários temas que são visíveis na escola (L1-CB).

Sim, mais de uma vez eu já presenciei preconceito racial. Alguns que se tratavam sobre sexualidade, sendo, às vezes, muito homofóbicos e, também, religiosos. A princípio eu fiquei paralisado [...] Mesmo sendo revoltante, sinceramente eu não consegui intervir (L2-CB).

O preconceito na escola acontece, mas, por vezes, ele passa como despercebido. Já está tão "naturalizado" que os alunos se chamam de "macaco" ou "carvãozinho". E você observa isso até mesmo entre as crianças negras. Por isso, vejo que é necessário, sim, debater essas questões na escola (L3-G).

A escola é um ambiente muito propício a momentos de preconceito por haver choques de pensamentos; então, em um determinado dia eu presenciei uma situação de racismo disfarçada de "brincadeira" entre os alunos. Era um garoto negro e homossexual, e os colegas diziam para ele escrever com o dedo porque iria sair tinta preta e que quando ele corre, ao suar, cai petróleo no chão (L4-G).

Segundo Oliveira (2017, p. 133), “[...] a cada passo que nossa sociedade dá é nítido como há um aumento de pessoas que se julgam superiores ou melhores seja por causa de sua cor de pele, seu segmento religioso, seu gênero ou influência cultural. Esse tipo de comportamento gera o que chamamos de preconceito". As experiências vivenciadas se aproximam dos relatos de Saavedra et al. (2003, p. 41), que associam a discriminação racial a "[...] sentimentos de angústia, sofrimento e indignação", que levaram os licenciandos a se posicionarem contra situações de preconceito. 
O preconceito racial é evidenciado nas narrativas de L1-CB, L3-G e L4-G. Os relatos dos licenciandos indicam que o preconceito racial está presente na escola e que este traz consigo uma carga de inferiorização por meio da hostilidade e do menosprezo por "[...] pessoas ou grupos humanos cujas características, hierarquicamente tidas como inferiores', estariam condicionadas as suas características 'raciais'" (SANTIAGO; AKKARI; MARQUES, 2013, p. 119). Nota-se a urgência de se pensar uma escola aberta ao debate e à reflexão-crítica sobre as diferenças dos sujeitos que convivem neste espaço, fazendo valer uma proposta curricular que rompa com as práticas eurocêntricas e monoculturais e busque fomentar o debate racial no cotidiano escolar não como algo pontual e folclorizado. Neste sentido, a elaboração de um currículo que entende no conflito a possibilidade de diálogo e reflexão corrobora para uma direção ética que aponta para "[...] a liberdade, e não para o aprisionamento do sujeito no preconceito, na desigualdade, na discriminação e no racismo" (GOMES, 2013, p. 83). Para que tal perspectiva seja alcançada é relevante que questões étnico-raciais sejam discutidas na escola e na formação inicial e continuada de professores.

As questões de gênero e sexualidade aparecem nas narrativas dos licenciandos L2CB e L4-G como situações de preconceito presenciadas no cotidiano escolar. Essas questões ainda estão marcadas pela desigualdade e pelo binarismo homem e mulher, muitas vezes em uma relação hierárquica de poder. O padrão heteronormativo desconhece qualquer forma de expressão da sexualidade que foge ao binarismo citado. Carvalho (2013, p. 112) afirma que "[...] certos referenciais de masculinidade e de heterossexualidade" interferem nos comportamentos dos sujeitos na escola, o que estimula atitudes de preconceito para com aqueles que "fogem" ao padrão heteronormativo. Em alguns casos, a escola deslegitima a homossexualidade por entender que é um tema inapropriado para os alunos. Para Lopes (2013, p. 138), novas práticas propositivas para abordar questões de gênero e sexualidade fundamentam uma "[...] arena de naturalização e normatividade tanto no que diz respeito à heteronormatividade compulsória como também o ideal de uma identidade homossexual homogênea". Ao trazer essas questões para o debate, a escola permite valorizar as diferentes identidades do movimento LGBTQI+.

Os licenciandos também expuseram que os alunos demonstraram atitudes por eles denominadas de "brincadeiras", mas que indicavam preconceito:

Houve também uma situação em que os alunos faziam "brincadeiras" sobre a sexualidade de outros alunos (L1-CB).

É curioso que muitos alunos são preconceituosos, mas eles acham que certos tipos de atitudes são "brincadeiras", mas não são. Quando uma pessoa está sendo ferida por um comentário já não podemos tratar isso como brincadeira (L2-CB).

São atitudes disfarçadas de "brincadeira", mas que nós bolsistas percebemos que se tratava de uma abordagem racista; então, propomos uma atividade com a turma e, a partir de uma conversa, explicamos que isso não era uma brincadeira e que existem pessoas diferentes que precisamos respeitar (L4-G).

Já observei sim, principalmente com relação às pessoas que estão fora do peso "ideal". Certas brincadeiras passam despercebidas, mas, principalmente os gordinhos, sofrem com isso. Sempre que percebo essas situações eu busco sentar com os alunos e conversar para explicar que essas posturas não são corretas (L5-M). 
As "brincadeiras" narradas pelos licenciandos podem ser interpretadas como sendo fruto do daltonismo cultural presente na escola, pois, embora os indivíduos possam ser conscientes "[...] das diferenças culturais presentes na sala de aula", acabam por centrarem-se "[...] predominantemente no grupo considerado padrão" (CANDAU, 2014b, p. 39) e banalizarem as diferenças, culturas e opções dos indivíduos neste espaço, de modo a contribuir para a "naturalização" do preconceito e discriminação na escola. Para Martinazzo, Schmidt e Burg (2014), a escola, como um local de diversidade, pode promover estratégias que tenham como foco o reconhecimento das diferenças, para, assim, desenvolver diálogos que fomentem respeito, liberdade e solidariedade entre os diferentes sujeitos. Neste sentido, a escola crítica e reflexiva ajuda os sujeitos a "[...] aprender a conviver, vivendo a própria cultura e respeitando as diferentes formas de expressão cultural (MARTINAZZO; SCHMIDT; BURG, 2014, p. 15). Santiago, Akkari e Marques (2013) propõem que:

[...] a diferença como elemento constituidor do ser humano e a educação como direito assegurado a todos indivíduos nos desafiam a pensar estratégias que possibilitem articular o processo educacional e as diferenças para além das práticas homogeneizadoras e monoculturais presentes no cotidiano escolar (p. 42-43).

Os relatos dos licenciandos apontaram as contribuições do Pibid na sua formação inicial ao vivenciarem experiências próprias do cotidiano escolar. Segundo Zeulli et al. (2012, p. 14), é "[...] essencial o contato e a inserção do licenciando no ambiente escolar, próprio da realização de sua profissão docente, para que se inteire de sua realidade, dos problemas e desafios enfrentados pela equipe da escola", inserção que vem sendo proporcionada pelo Pibid e contribuindo para uma formação docente contextualizada, com aproximação de teoria e prática, além de introduzi-lo na realidade da escola (RAUSCH; FRANTZ, 2013).

Houve mudança no meu crescimento profissional. O Pibid me ajudou a ir à frente da sala de aula e compartilhar as minhas ideias, opiniões e escutar nossos alunos. Melhorou muito minha relação com os alunos enquanto licencianda. Dar a "cara a tapa" foi um grande crescimento e aprendizado para mim [risos] (L1-CB).

$\mathrm{O}$ Pibid permite várias mudanças. Com a experiência que tive pude perder a timidez e me aventurar em atividades em sala de aula. Acredito que me capacitou para dar aula por ter permitido trabalhar com diferentes estratégias pedagógicas (L2-CB).

Hoje tenho uma visão de escola totalmente diferente. Vejo como é a relação professor e aluno e como está ganhando espaço na sala de aula. O Pibid como projeto de formação de professores foi muito importante para a minha formação profissional. Os três anos de Pibid foram importantes para eu entender o contexto escolar, como funciona um projeto desenvolvido na escola e, também, a escrever artigos científicos para apresentar em eventos. Não foi a faculdade que me ensinou isso; eu aprendi tudo isso graças ao Pibid (L3-G).

O projeto Pibid, por ter como característica a promoção de atividades no ambiente escolar, me possibilitou vivenciar experiências de diálogo com professores de outras disciplinas escolares (...) além de permitir enxergar a escola como um grande palco que permite a realização desses momentos de troca de experiências com relação à variedade de cultura que existe na escola (L4-G). 
A gente começa a se moldar e hoje eu estou bem diferente do que eu era. Mudei o modo de falar, explicar o conteúdo, ou seja, sou outra licencianda; bem melhor do que antes (L5-M).

A análise das vozes desses licenciandos ressalta a contribuição do Pibid para uma aproximação de saberes entre as disciplinas escolares e a abordagem cultural de que tanto a escola carece em tempos atuais. Por outro lado, nota-se que os licenciandos ainda apresentavam limitações para aproximar conteúdos das disciplinas escolares com os saberes necessários para uma educação voltada para a interculturalidade na escola. Percebe-se a importância dada pelos licenciandos ao Pibid como programa que contribui para a formação docente desses sujeitos. As experiências formativas desses pibidianos aproximam-se dos resultados de pesquisa de Zeulli et al. (2012), pois relatam aprender a "[...] se comportar e resolver os problemas na sala de aula, entender e trabalhar meIhor com os conteúdos, lidar com os alunos, buscar novas metodologias e adquirir mais segurança e autoconfiança" para lidar com os assuntos do cotidiano escolar. Queiroz e Neves (2016, p. 255) destacam a importância da constituição de professores em uma perspectiva de formação inicial e continuada de modo que permita a "[...] reelaboração constante dos saberes que realizam em sua prática, confrontando suas experiências nos contextos escolares onde atuam".

\section{CONCLUSÃO}

Os resultados apontam para a realização de práticas de ensino e projetos com a finalidade de potencializar o diálogo e a reflexão sobre o reconhecimento e a valorização de diferentes culturas na escola. Práticas dialógicas foram destacadas como estratégias norteadoras das discussões sobre abordagens culturais, como forma pela qual diferentes vozes pudessem ser ouvidas e valorizadas sem que fossem descaracterizadas por uma visão assimilacionista, proporcionando igualdade na diferença dos indivíduos em processo de aprendizagem.

A análise das narrativas indicou obstáculos que dificultam as práticas pedagógicas que, por vezes, são produtos do preconceito velado e enraizado na escola. Os licenciandos buscaram maneiras para abordar a diversidade cultural no ambiente escolar, perpassando por motivações pessoais de quem presenciou o sofrimento com o preconceito e a discriminação neste. Mesmo havendo diferentes projetos e debates que buscavam minimizar tais atitudes, a análise dos relatos indicou preconceito racial e de gênero na escola, sendo esses naturalizados pelo daltonismo cultural dos sujeitos na forma de "brincadeiras".

Para os licenciandos, a vivência no ambiente escolar contribuiu para uma amálgama entre os saberes pessoais e os saberes adquiridos pela experiência no tempo de vivência com os diferentes sujeitos nesse espaço. A experiência proporcionada pelos subprojetos do Pibid potencializou que tais licenciandos mobilizassem saberes e fazeres direcionados para uma educação intercultural em suas práticas cotidianas na educação básica. Neste sentido, entende-se a importância da valorização de projetos que estreitem os laços com a universidade e a escola e que contribuam para a formação inicial e continuada de licenciandos e professores da educação básica, com práticas dialógicas 
como estratégia para problematizar a lógica monocultural e contribuir para o reconhecimento e a valorização da diferença, rompendo com a ideia de uma educação excludente e homogeneizadora.

\section{REFERÊNCIAS}

AMBRoSetTI, N. B.; NASCIMENTO, M. G. C. A.; ALMEIDA, P. A.; CALIL, A. M. G. C.; PASSOS, L. F. Contribuições do Pibid para a formação inicial de professores: o olhar dos estudantes. Educação em Perspectiva, Viçosa, 4(1), p. 151-174, 2013. Disponível em: https://periodicos.ufv.br/ojs/educacaoemperspectiva/article/view/6615/2722. Acesso em: 10 jan. 2019.

ANDRADE, M. O ensino de Filosofia como ética intercultural. In: MOREIRA, A. F.; CANDAU, V. M. (org.). Currículos, disciplinas escolares e culturas. Petrópolis, RJ: Vozes, 2014. p. 318-352.

ANDRADE, M. Sobre o conceito de tolerância: relações entre religião e filosofia e suas potencialidades educativas. In: ENCONTRO NACIONAL DE DIDÁTICA E PRÁTICAS DE ENSINO, 16., 2012. Campinas, 2012. p. 1-12.

BARCELLOS, J.; ANDRADE, M. A religião entra na escola pública: uma análise da intolerância religiosa na escola. In: ENCONTRO NACIONAL DE DIDÁTICA E PRÁTICAS DE ENSINO, 17., 2014. Ceará, 2014. p. 1-13. Disponível em: http://www.uece.br/endipe2014/ebooks/livro3/88\%20A\%20RELIGI\%C3\%830\%20 ENTRA\%20NA\%20ESCOLA\%20P\%C3\%9ABLICA\%20UMA\%20AN\%C3\%81LISE\%20DA\%20INTOLER\%C3\%82NCIA\%20RELIGIOSA\%20NA\%20ESCOLA.pdf. Acesso em: 5 dez. 2018.

BARDIN, L. Análise de conteúdo. São Paulo: Edições 70, 2016. 279 p.

BARRETO, E. S. S. Políticas de formação docente para a educação no Brasil: embates contemporâneos. Revista Brasileira de Educação, 20 (62), p. 679-701, 2015. Disponível em: http://www.scielo.br/pdf/rbedu/ v20n62/1413-2478-rbedu-20-62-0679.pdf. Acesso em: 14 jan. 2019.

BOGDAN, R.; BIKLEN, S. K. Investigação qualitativa em educação: uma introdução à teoria e aos métodos. Porto: Editora Porto, 1994. 335p.

BRASIL. Decreto n. 7219, de 24 de junho de 2010. Dispõe sobre o Programa Institucional de Bolsa de Iniciação à Docência - Pibid - e dá outras providências. Disponível em: http://www.planalto.gov.br/ccivil_03/_ato2007-2010/2010/decreto/d7219.htm. Acesso em: 14 jan. 2019.

BRASIL. Portaria normativa n. 38, de 12 de dezembro de 2007. Dispõe sobre o Programa de Bolsa Institucional de Iniciação à Docência - Pibid. Ministério da Educação. Diário Oficial, 2007, p. 239. Disponível em: https://www.capes.gov.br/images/stories/download/legislacao/Portaria_Normativa_38_PIBID.pdf. Acesso em: 14 jan. 2019.

CAMPOS, L. M. L.; DINIZ, R. E. S. A prática como fonte de aprendizagem e o saber da experiência: o que dizem professores de Ciências e Biologia. Revista Investigações em Ensino de Ciências, 6 (1), p. 79-96, 2001. Disponível em: https://www.if.ufrgs.br/cref/ojs/index.php/ienci/article/view/587/380. Acesso em: 5 dez. 2018.

CANDAU, V. M. F. Educação intercultural: entre afirmações e desafios. In: MOREIRA, A. F.; CANDAU, V. M. (org.). Currículos, disciplinas escolares e culturas. Petrópolis, RJ: Vozes, 2014a, p. 23-41.

CANDAU, V. M. F. Ser professor/a hoje: novos confrontos entre saberes, culturas e práticas. Revista Educação, 37 (1), p. 33-41, 2014b. Disponível em: http://revistaseletronicas.pucrs.br/ojs/index.php/faced/ article/view/15003/10923. Acesso em: 10 dez. 2018.

CANDAU, V. M. F. Diferenças culturais, cotidiano escolar e práticas pedagógicas. Revista Currículo sem Fronteiras, 11 (2), p. 240-255, 2011. Disponível em: http://www.curriculosemfronteiras.org/vol11iss2articles/candau.pdf. Acesso em: 10 dez. 2018.

CANDAU, V. M. F. Sociedade, cotidiano escolar e cultura(s): uma aproximação. Educação \& Sociedade, ano XXIII, 79, p. 125-161, 2002. Disponível em: http://www.scielo.br/pdf/es/v23n79/10852.pdf. Acesso em: 10 dez. 2018.

CANEN, A.; OLIVEIRA, A. M. A. Multiculturalismo e currículo em ação: um estudo de caso. Revista Brasileira de Educação, 21, p. 61-75, 2002. Disponível em: http://www.scielo.br/pdf/rbedu/n21/n21a05.pdf. Acesso em: 10 dez. 2018.

CANEN, A.; ARBACHE, A.P.; FRANCO, M. Pesquisando multiculturalismo e educação: o que dizem as dissertações e teses. Educação \& Realidade, 26 (1), p. 161-181, 2001. Disponível em: https://seer.ufrgs.br/ educacaoerealidade/article/view/41321/26151. Acesso em: 6 dez. 2018. 
CARVALHO, M. P. Gênero na sala de aula: a questão do desempenho escolar. In: MOREIRA, A. F.; CANDAU, V. M. (org.). Multiculturalismo: diferenças culturais e práticas pedagógicas. 10. ed. Petrópolis, RJ: Vozes, 2013. p. 90-124.

DUARTE, R. Entrevistas em pesquisas qualitativas. Revista Educar, Curitiba-PR, 24, p. 213-225, 2004. Disponível em: http://www.scielo.br/pdf/er/n24/n24a11.pdf. Acesso em: 7 jan. 2019.

FERREIRO, E. Diversidad y proceso de alfabetización: de la celebración a la toma de conciencia. Lectura y vida: Revista Latinoamericana de Lectura, 15 (3), p. 1-11, 1994.

FLEURI, R. M. Desafios à educação intercultural no Brasil. Educação, Sociedade \& Cultura, 16, p. 45-62, 2001.

GIL, A. C. Como elaborar projetos de pesquisa. 4. ed. São Paulo: Atlas, 2002. 175p.

GOMES, N. L. A questão racial na escola: desafios colocados pela implantação da Lei 10.639/03. In: MOREIRA, A. F.; CANDAU, V. M. (org.). Multiculturalismo: diferenças culturais e práticas pedagógicas. 10. ed. Petrópolis, RJ: Vozes, 2013. p. 67-89.

JACOB, E. Classification and categorization: a difference that makes a difference. Library Trends, 52 (3), p. 515-540, 2004.

LAMEGO, C. R. S.; SANTOS, M. C. F. Multiculturalismo e educação intercultural: narrativas de professores sobre preconceito e abordagens culturais na escola. Dialogia, São Paulo, n. 29, p. 111-121, maio/ ago.2018. Disponível em: http://periodicos.uninove.br/index.php?journal=dialogia\&page=article\&op=view\&path\%5B\%5D=8810\&path\%5B\%5D=4947. Acesso em: 5 abr. 2019.

LOPES, L. P. M. Sexualidade em sala de aula: discurso, desejo e teoria queer. In: MOREIRA, A. F.; CANDAU, V. M. (org.). Multiculturalismo: diferenças culturais e práticas pedagógicas. 10. ed. Petrópolis, RJ: Vozes, 2013. p. $125-148$.

MARANDINO, M.; SELLES, S. E.; FERREIRA, M. S. Ensino de Biologia: histórias e práticas em diferentes espaços educativos. 1. ed. São Paulo: Editora Cortez, 2009. p. 215.

MARTINAZZO, C. J.; SCHMIDT, A.; BURG, C. I. Identidade e diversidade cultural no currículo escolar. Revista Contexto \& Educação, 29 (92), p. 4-20, 2014. Disponível em: https://www.revistas.unijui.edu.br/index. php/contextoeducacao/article/view/1671. Acesso em: 24 jan. 2019.

MATOS, D. C. V. S.; PERMISÁN, C. G. Educação intercultural e formação de professores em contexto espanhol para alunos imigrantes. Revista Educação e Pesquisa, 42 (4), p. 1.093-1.108, 2016. Disponível em: http://www.scielo.br/pdf/ep/v42n4/1517-9702-ep-42-04-1093.pdf. Acesso em: 15 jan. 2019.

MELO, R. A.; FRANÇA-CARVALHO, A. D. Contribuições do Pibid para a formação de professores de biologia. Crítica Educacional, Sorocaba-SP, 3 (2), Especial, p, 465-478, 2017. Disponível em: http://www.criticaeducativa.ufscar.br/index.php/criticaeducativa/article/view/111/306. Acesso em: 20 dez. 2018.

MINAYO, M. C. de S. Pesquisa social: teoria, método e criatividade. 23. ed. Petrópolis, RJ: Vozes, 2009. p. 108.

MONTEIRO, A. M. F. C. Formação docente: território contestado. In: MARANDINO, M.; SELLES, S. E.; FERREIRA, M. S.; AMORIM, A. C. (org.). Ensino de Biologia: conhecimentos e valores em disputa. Niterói-RJ: Eduff, 2005.

MONTEIRO, A. M. F. C. Entre saberes e práticas: a relação de professores com os saberes que ensinam. In: Reunião Anual da ANPED, 26., Poços de Caldas-MG, 2003, p. 1-12. Disponível em: http://www.anped.org. $\mathrm{br} / \mathrm{sites} /$ default/files/4_entre_saberes_e_praticas.pdf. Acesso em: $20 \mathrm{dez} .2018$.

MORAES, R. Análise de conteúdo. Revista Educação, Porto Alegre, 22 (37), p. 7-32, 1999. Disponível em: https://edisciplinas.usp.br/pluginfile.php/4125089/mod_resource/content/1/Roque-Moraes_Analise\%20de\%20conteudo-1999.pdf. Acesso em: 20 dez. 2018.

MOREIRA, A. F. B.; CANDAU, V. M. Educação escolar e cultura(s): construindo caminhos. Revista Brasileira de Educação, 23, p. 156-168, 2003. Disponível em: <http://www.scielo.br/pdf/rbedu/n23/n23a11>. Acesso em: 20 dez. 2018.

NÓVOA, A. Tempos da escola no espaço: Portugal-Brasil-Moçambique: dez digressões sobre um programa de investigação. Revista Currículo sem Fronteiras, 1 (2), p. 131-150, 2001. Disponível em: http://www.periodicos.uem.br/ojs/index.php/rbhe/article/view/38755/20285. Acesso em: 15 dez. 2018.

OLIVEIRA, A. F. C. Preconceito na escola. Revista InterAtividade, Andradina-SP, 5 (1), p. 133-146, 2017. Disponível em: http://www.firb.br/editora/index.php/interatividade/article/view/219/316. Acesso em: 22 jan. 2019.

POMMER, R. G.; SANTOS, J. R. Q.; SOARES, A. L. R. Pibid História/UFSM: possibilidades para uma educação intercultural. Métis: História \& Cultura, 15 (29), p. 60-76, 2016. Disponível em: http://www.ucs.br/ etc/revistas/index.php/metis/article/view/4478/2553. Acesso em: 22 jan. 2019. 
QUEIROZ, P. P.; NEVES, F. H. G. A formação do professor de sociologia e a educação intercultural. In: Atas Investigação Qualitativa em Educação, 1, p. 250-259, 2016.

RAUSCH, R. B.; FRANTZ, M. J. Contribuições do Pibid à formação inicial de professores na compreensão de licenciandos bolsistas. Atos de Pesquisa em Educação, 8 (2), p. 620-641, 2013. Disponível em: http:// proxy.furb.br/ojs/index.php/atosdepesquisa/article/view/3825/2425. Acesso em: 5 jan. 2019.

RECH, I.; BREZOLIN, C. F.; OLIVEIRA, V. F. Escola e universidade: a união capaz de ressignificar novas formas à formação dos professores. In: ANPED Sul, 9., Caxias do Sul: Universidade Caxias do Sul, 2012, p. 1-14. Disponível em: http://www.ucs.br/etc/conferencias/index.php/anpedsul/9anpedsul/paper/viewFile/1175/453. Acesso em: 15 dez. 2018.

RIOS, J. A. V. P.; NUÑEZ, J. M. L.; FERNANDEZ, O. F. R. L. Diversidade na educação básica: políticas de sentidos sobre a formação docente. Revista da FAEEBA - Educação e Contemporaneidade, Salvador, 25 (45), p. 101-112, 2016. Disponível em: https://www.revistas.uneb.br/index.php/faeeba/article/view/2288/1594. Acesso em: 10 jan. 2019.

SAAVEDRA, A.; LUCINDA, M. C.; RAMIREZ, J.; SOUZA, M.; GUERZOLA, M.; MORGADO, P.; SACAVINO, S.; CANDAU, V. M. F. In: CANDAU, V. M. F. (org.). Somos tod@s iguais? Escola, discriminação e educação em direitos humanos. Rio de Janeiro: DP\&A, 2003. p. 174.

SACAVINO, S. Interculturalidade e educação: desafios para a reinvenção da escola. In: ENCONTRO NACIONAL DE DIDÁTICA E PRÁTICAS DE ENSINO, 16., Campinas, 2012, p. 1-13.

SANTIAGO, M.; AKKARI, A.; MARQUES, L. P. Educação intercultural: desafios e possibilidades. Petrópolis, RJ: Vozes, 2013. 194p.

TARDIF, M. Saberes docentes e formação profissional. 17. ed. Petrópolis: Ed. Vozes, 2014. 325 p.

TRIVIÑOS, A. N. S. Introdução à pesquisa em ciências sociais: a pesquisa qualitativa em educação. São Paulo: Atlas, 1987. 175p.

WALSH, C. Interculturalidad crítica y educación intercultural. In: SEMINARIO INTERCULTURALIDAD Y EDUCACIÓN INTERCULTURAL, La Paz, 2009, p. 1-18.

ZEULLI, E.; BORGES, M. C.; ALVES, V. A.; JÚNIOR, A. P. O. O Pibid e a formação inicial de professores da UFTM: diferentes experiências entre seus atores. In: ENCONTRO NACIONAL DE DIDÁTICA E PRÁTICAS DE ENSINO, 16., Campinas, 2012, p. 12-24. 